\title{
Anger at NZ plan to target social goals in research
}

[SYDNEY] Scientists in New Zealand are facing another major restructuring of government research funding, following extensive reforms eight years ago.

New measures announced last month from the country's Foresight programme aim to redirect half of the NZ\$600 million (US\$320 million) science budget to supporting research relevant to achieving social in addition to economic goals.

The reforms, which will affect New Zealand's NZ\$300 million Public Good Science Fund, have angered many in the academic research community, not just because of the speed and scale of the changes, but also owing to a decision to reduce the use of academic peer review to allocate funding.

Groups made up of industrialists, scientists and community organizations will be invited to submit ideas for 'portfolios' of medium-term projects lasting five to six years. Final decisions on funding will be made by the government following advice from the Foundation for Research, Science and Technology (FRST), which administers the so-called Public Good Fund. Previous allocations from this fund were typically for single projects worth around NZ\$500,000 over three years.

The priorities of the current Foresight programme have been replaced by 17 'outcomes' for research that are expressed as generalized, social goals. These include:

- A culture of innovation, anticipation and creation of new markets;

- Empowered individuals and commu nities;

- High health status;

- Healthy, diverse, resilient ecosystems;

- Maori development, distinctive and

positive cultural identity; and

- Self-determination and ethical principles.

The government says the reforms are not intended to relax efforts to forge partnerships between universities and industry. Prime minister Jenny Shipley has directed Max Bradford, the new minister for tertiary education, to collaborate with the minister for research, science and technology, Maurice Williamson, and the government's Crown Research Institutes to direct universities to align themselves closer to industry.

But biomedical researchers are particularly concerned about the reforms. They are lobbying the Health Research Council not to allow its budget to be influenced by the new Foresight priorities or the new method of allocating funds.

Janet Grieve, president of the New Zealand Association of Scientists and a senior government researcher, last week

wrote to the prime minister and the cabinet complaining that the "unspecified methodology [for funding allocation] is causing great disquiet and anxiety among scientists".

Michael Berridge, the association's secretary, is another prominent critic. He argues that the reforms are "based on pure faith". And he adds that more weight should be given to scientific merit than relevance to society in allocating research funds.

Paul Callaghan, a leading physicist at Massey University and president-elect of the academy council of the Royal Society of New Zealand, is also concerned. Callaghan believes that core disciplines such as physics will suffer if they can only "piggy back on to an applied portfolio". Criticism has also come from Michael Irving, vice-chancellor of Victoria University of Wellington.

But the reforms have been welcomed by the leaders of the government-owned Crown Research Institutes, which derive most of their income from the Public Good Science Fund. Support has also come from the FRST.

Stephen Thompson, the foundation's chief executive, claims that the new priorities will "encourage creativity" and are well suited to science in a small country. But he acknowledges that the new model has no parallels in other countries.

The reforms carry the enthusiastic support of Prime Minister Shipley, who told parliament that they are aimed at making science more relevant to the wider community. The government's longer-term aim is to use the reforms to illustrate to politicians the need to increase overall levels of research funding, say proponents of the measures.

But Shipley, who leads the conservative National Party, is in a politically precarious

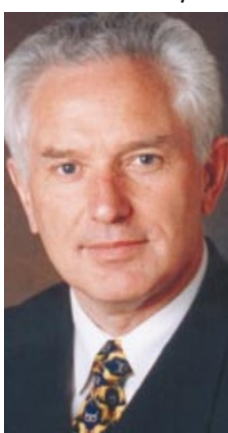

Bradford: work with industry. than the author of the proposals, his predecessor, Wyatt Creech (see Nature 396, 502; 1998). Bradford has delayed legislation for the time being. Creech was recently appointed deputy prime minister in a ministerial reshuffle.
PeterPockley

\section{Brazilian scientists team up for cancer genome project}

[SÃO PAULO] Brazilian researchers have entered the competitive field of human genome sequencing with the signing of an agreement between the state funding agency of São Paulo (FAPESP) and the US-based Ludwig Institute for Cancer Research.

Each will contribute US\$5 million to a two-year Human Cancer Genome Project. According to FAPESP, the programme is "aimed at providing sequences from genes expressed in tumours that are important within the context of public health in the state of São Paulo".

The project will sequence and analyse short DNA fragments created from the central coding portions of human genes. Although a US patent is being sought for the technique used to generate these expressed sequence tags (ESTs), the sequences will be freely available on the Internet. "No sequences will be patented. All the data will be promptly published," says Ed McDermott Jr, president of the Ludwig Institute, who visited Brazil to sign the agreement.

The programme follows on from the Organization for Nucleotide Sequencing and Analysis (ONSA), a network of 30 laboratories in the state of São Paulo now in the final steps of sequencing the complete genome of the plant pathogen Xylella fastidiosa. The groups will build upon their experience with this pathogen, which causes many economically important plant diseases, notably citrus variegated chlorosis, which poses a major threat to São Paulo's orange farming (see Nature 389, 654; 1997).

ONSA is a 'virtual' institute that links the sequencing laboratories, keeping down costs and red tape. The acronym, which sounds like the word onça (jaguar) in Portuguese, mimics the Institute for Genomic Research (TIGR), according to José Fernando Perez, FAPESP's scientific director.

Five centres will carry out the sequencing, each helped by four other labs. The centres will be at the chemistry institute, the faculty of medicine at São Paulo, and the faculty of medicine at Ribeirão Preto, all from the University of São Paulo; at the Paulista School of Medicine, São Paulo; and at the Hemocentro of the University of Campinas. The programme aims to generate between 500,000 and 750,000 EST sequences, and about 200 million bases of human genome sequence.

The project will be monitored by a fourmember steering committee, composed of Marcelo Bento Soares of the University of Iowa, John Sgouros of the Imperial Cancer Research Fund in London, and Webster Cavenee and Richard Kolodner of the Ludwig Institute in San Diego. Ricardo Bonalume Neto 